\title{
Turismo de base comunitária e relação de poder no Parque Nacional Marinho de Fernando de Noronha (Brasil)
}

Community-based tourism and power relation on the Fernando de Noronha National Marine Park (Brazil)

El turismo comunitario y las relaciones de poder en el Parque Nacional Marino de Fernando de Noronha (Brasil) http://dx.doi.org/10.18472/cvt.18n2.2018.1332

Carolina Dutra de Araújo < dutracarolina@gmail.com > Georg-August-Universität-Göttingen, Göttingen, Alemanha

Débora Regina Campos Cândido <drccandido@gmail.com > Universidade Federal Rural do Rio de Janeiro (UFRRJ), Nova Iguaçu, RJ, Brasil

Max Krott <mkrott@gwdg.de >

Georg-August-Universität-Göttingen, Göttingen, Alemanha

CRONOLOGIA DO PROCESSO EDITORIAL

Recebimento do artigo: 13-set-2016

Aceite: 23-abril-2018

FORMATO PARA CITAÇÃO DESTE ARTIGO

ARAÚJO, C. D. de.; CÂNDIDO, D. R. C.; KROTT, M. Turismo de base comunitária e relação de poder no Parque Nacional Marinho de Fernando de Noronha (Brasil). Caderno Virtual de Turismo. Rio de Janeiro, v. 18, n. 2, p. 155-172, ago. 2018.

REALIZAÇÃO

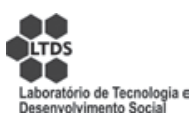

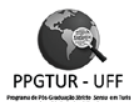

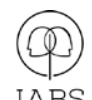

APOIO INSTITUCIONAL

EDIÇÃO

PATROCÍNIO

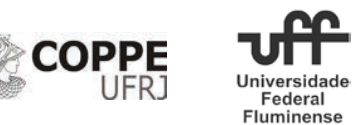

EDITQRA 


\section{RESUMO}

O turismo de base comunitária pode ser uma alternativa para o desenvolvimento do turismo na medida em que este promove o empoderamento das comunidades locais nos processos de tomada de decisão. Entretanto, os diferentes interesses dos atores envolvidos apresentam-se como entraves a essa alternativa. O objetivo deste estudo é identificar os elementos de poder dos atores mais poderosos que exercem influência no Parque Nacional Marinho de Fernando de Noronha, a fim de analisar se há condições de desenvolvimento de turismo de base comunitária na ilha, de acordo com o apoio desses atores. Para tanto, foi analisada a distribuição de poder entre os atores levando-se em consideração coerção, incentivos e desincentivos, e informação dominante por meio de entrevistas com oito atores considerados mais poderosos, com interesse em turismo no local. Acredita-se que quando os interesses dos atores mais poderosos são contemplados, o planejamento do turismo pode ser mais efetivo. Nesse contexto, o turismo de base comunitária emerge como uma das alternativas possíveis para um desenvolvimento turístico mais justo para as comunidades locais. Os resultados indicam que há algum apoio ao turismo de base comunitária por parte dos entrevistados, entretanto, o cenário observado é de excessiva valorização do conhecimento técnico, notadamente por ser uma área protegida, o que afasta o residente dos processos de tomada de decisão.

Palavras-chave: Turismo de base comunitária. Poder. Interesses.

\section{ABSTRACT}

Community-based tourism can be an alternative to the development of tourism as it promotes the empowerment of local communities in decision-making processes. However, the different interests of the actors involved present themselves as obstacles to this alternative. The objective of this study is to identify the power elements of the most powerful actors that influence the Fernando de Noronha National Marine Park, in order to analyze if there are conditions for the development of community-based tourism in the island, according to the support of these actors. In order to do so, the distribution of power among the actors was analyzed taking into account coercion, incentives and disincentives and dominant information through interviews with eight actors considered the most powerful, with interest in the tourism activity in the area. It is believed that when the interests of the most powerful actors are contemplated, tourism planning can be more effective. In this context, community-based tourism emerges as one of the possible alternatives for a fairer tourism development for local communities. The results indicate that there is some support to communitybased tourism by the interviewees, however the scenario observed is of an excessive appreciation of technical knowledge, especially because it is a protected area, which distracts the resident from the decision-making processes.

Keywords: Community-based tourism. Power. Interests.

\section{RESUMEN}

El turismo comunitario puede ser una alternativa para el desarrollo del turismo en la medida en que éste promueve el empoderamiento de las comunidades locales en los procesos de toma de decisiones. Sin embargo, los diferentes intereses de los actores involucrados se presentan como obstáculos a esa alternativa. El objetivo de este estudio es identificar los elementos de poder de los actores más poderosos que ejercen influencia en el Parque Nacional Marino de Fernando de Noronha, a fin de analizar si hay condiciones de desarrollo de turismo comunitario en la isla, de acuerdo con el apoyo de esos actores. Para ello, se analizaron la distribución de poder entre los actores tomando en consideración coerción, incentivos y desincentivos e información dominante a través de entrevistas con ocho actores considerados más poderosos, con interés en el turismo en el lugar. Se cree que cuando los intereses de los actores más poderosos son contemplados, la planificación del turismo puede ser más efectiva. En este contexto, el turismo comunitario emerge como una de las alternativas posibles para un desarrollo turístico más justo para las comunidades locales. Los resultados indican que hay algún apoyo al turismo de base comunitaria por parte de los entrevistados, sin embargo el escenario observado 
es de excesiva valorización del conocimiento técnico, notadamente por ser un área protegida, lo que aleja al residente de los procesos de toma de decisión.

Palavras clave: Turismo comunitario. Poder. Intereses.

\section{INTRODUÇÃO}

O turismo de base comunitária oferece uma alternativa de desenvolvimento turístico participativo que busca incluir a comunidade local no processo de planejamento e tomadas de decisão sobre seu território. Entretanto, o conflito de interesses dos vários atores envolvidos é um entrave para sua plena implementação.

As teorias de poder podem identificar esses interesses por meio de seus elementos: coerção, incentivos e desincentivos, e informação dominante, além de definir quais são os atores mais poderosos que exercem influência sobre o desenvolvimento turístico de um determinado local.

O Parque Nacional Marinho de Fernando de Noronha é uma unidade de conservação de proteção integral cujo planejamento e controle de visitação são referências no turismo brasileiro. Porém, a parceria público-privada estabelecida em 2010 é considerada pouco inclusiva para visitantes de classes econômicas mais baixas.

Nesse contexto, as teorias de poder podem elucidar sua distribuição e identificar algumas alternativas para o sucesso do planejamento turístico. Portanto, acredita-se que para que o conceito de turismo de base comunitária funcione na prática é necessário que os conflitos de interesses sejam contemplados no processo de planejamento, buscando um modelo de desenvolvimento mais justo para as comunidades locais.

Assim, o objetivo deste estudo é identificar os elementos de poder dos atores mais poderosos, definidos por meio do processo de bola de neve (VINUTO, 2014) e entrevistas semiestruturadas (GIL, 1987), que exercem influência no Parque Nacional Marinho de Fernando de Noronha (Pernambuco, Brasil), a fim de analisar se há condições de desenvolvimento de turismo de base comunitária na ilha, de acordo com o apoio desses atores. Para tanto, foi analisada a distribuição de poder entre os atores levando-se em consideração coerção, incentivos e desincentivos, e informação dominante por meio da realização das entrevistas com oito atores considerados mais poderosos, com diversos interesses envolvendo o turismo no local.

Os resultados demonstram que há alto controle sobre o território do parque, com pouca participação local nos processos de tomada de decisão.

\section{Turismo de base comunitária: em busca do empoderamento das comunidades locais}

Entre as diversas definições de turismo de base comunitária é possível identificar alguns aspectos em comum em suas características, como uma atividade que gera benefícios econômicos para a 
comunidade, sendo planejado e administrado por esta (MITRAUD, 2003), baseada na preservação ambiental e no modo de vida local por meio da cooperação e distribuição dos benefícios gerados pelo turismo (MALDONADO, 2009). No Brasil, o Plano Nacional de Turismo 2007-2010 (2007) acrescenta que iniciativas de turismo de base comunitária podem ser vetor de redução de desigualdades sociais e distribuição de renda.

Em meados da década de 1980, a participação comunitária começa a ser identificada como fundamental para o sucesso de empreitadas turísticas. Nesse contexto, Haywood (1988) afirma que uma agenda turística pode ser mais bem-sucedida quando aplicadas técnicas de cooperação com comunidades locais. $\mathrm{Na}$ década de 1990, Simmons (1994) sinalizava a necessidade do envolvimento comunitário no planejamento turístico afirmando que a maioria dos impactos causados pelo turismo é sentida pelos residentes e que estes são parte fundamental da atmosfera de hospitalidade local. Nesse momento ainda não havia, no entanto, maior preocupação em utilizar-se dos saberes locais para o manejo da área. Keogh (1990), por sua vez, investigava que o estabelecimento de áreas protegidas ocorria sem participação popular, deliberadamente impondo uma nova realidade aos moradores locais. $\mathrm{O}$ autor observa que a participação local promove o intercâmbio de informações, gerando transparência na gestão turística local.

Para o planejamento do turismo de base comunitária, a participação da população local é um prérequisito para garantir a legitimidade, representatividade e sucesso em ações do projeto. Contudo, Getz e Jamal (1995) ressaltam a complexidade de iniciativas comunitárias devido à diversidade de interesses dos atores envolvidos e da realidade local, o que requer diferentes técnicas de colaboração adequadas à natureza e características dessas relações.

Essas questões estão relacionadas com o conceito de empoderamento recentemente incluído no planejamento do turismo, que é uma meta a ser alcançada pelos planejadores no que diz respeito à formulação de políticas e no desenvolvimento sustentável. De acordo com Jones (2005), um alto nível de controle da comunidade é desejável para maximizar os benefícios para a comunidade, mas é difícil encontrar lugares onde esses pressupostos são efetivamente aplicados na prática. No Brasil e em muitos países em desenvolvimento, o poder de tomada de decisão é muitas vezes delegado aos poderosos agentes externos (empresários que vislumbram grandes oportunidades em locais turísticos). Além disso, todos os atores envolvidos têm objetivos e interesses diversos, o que torna um processo colaborativo difícil, e capacitação local leva tempo.

Para o propósito deste estudo, define-se o turismo de base comunitária como aquele que capacita e incentiva as comunidades locais em todos os processos de tomada de decisão, gerando os seguintes resultados de acordo com Mitraud (2003, p. 24-25):

- Contribuir para a conservação do meio ambiente;

- Promover os valores culturais das comunidades, bem como a sua capacidade de gestão participativa;

- Promover a diversificação econômica para melhorar a qualidade de vida das comunidades;

- Contribuir para a integração e o equilíbrio entre a conservação ambiental, o respeito pela cultura local e diversificação das atividades econômicas. Deve ser realizado por meio de um processo participativo.

Hallack et al. (2011) enfatizam que não se trata de um segmento turístico, e sim de uma prática turística que visa à conservação da natureza e valorização das comunidades no processo de tomada de decisão. Por 
isso deve ser entendida muito mais do ponto de vista do planejamento do que do mercado, pois deve fazer parte do conjunto de princípios e práticas que norteiam a proposta de desenvolvimento da atividade em uma localidade.

\begin{abstract}
Nesse sentido, diante do impacto do turismo tradicional, da "coisificação" do lugar, da desumanização do sujeito e das políticas hegemônicas de produção do espaço turístico, o turismo de base comunitária (TBC) vem se tornando prática comum em toda a América Latina. No Brasil, o TBC surge como uma modalidade turística ascendente, sobretudo em Unidades de Uso Sustentável e áreas de relevância ambiental, que em sua maioria albergam comunidades com poucas perspectivas econômicas (HALLACK et al., 2011, p. 10).
\end{abstract}

Outro ponto a ser o observado é a noção de desenvolvimento como uma meta para a comunidade e não somente para grupos restritos de investidores. A partir do turismo de base comunitária, entende-se que a comunidade, ao participar do processo de tomada de decisão, passa a tomar parte nos benefícios ocasionados pela atividade turística. Sob essa óptica, o planejamento criaria diretrizes mais amplas de desenvolvimento, levando em conta a sustentabilidade em todas as suas dimensões: ambiental, econômica e social.

O turismo de base comunitária figura como uma alternativa que visa o bem-estar da população receptora e que leva em consideração sua identidade de forma a ir além de "espetacularização" de seus modos de vida, ou seja, um turismo que privilegia saberes locais tende a considerar diversos grupos sociais no processo de tomada de decisão para o planejamento. Os saberes locais, nessa lógica, não se restringem à matéria para atrativos turísticos. Assim, práticas que visam atingir fins mercadológicos tendem a tomar tradições e costumes das comunidades, transformando-as em um espetáculo para consumo dos visitantes, tendo em vista que suas práticas e o ambiente em que vivem são importantes primeiro para a comunidade e só então deve ser considerada a relevância para visitantes.

Por exemplo, no caso de Fernando de Noronha, os moradores que possuem experiências próprias com a natureza - que é o objeto da visitação - são os que vivem as relações sociais e que subsistem da economia. Logo, suas percepções são importantes referências para um processo de planejamento.

Recorrendo à lógica da etnoconservação, é possível situar o turismo de base comunitária como uma possibilidade de se empregar os saberes comunitários na conservação da natureza. De acordo com Diegues (2005), as comunidades tradicionais conservam saberes sobre a natureza, seus ciclos e melhores formas de manejo que devem ser levados em consideração nas práticas de proteção aos sistemas naturais. $\mathrm{Na}$ medida em que essa comunidade está inserida no processo de decisão, seus saberes pertinentes ao manejo serão considerados no processo de planejamento, possibilitando novas iniciativas de conservação. Ainda que as comunidades de Fernando de Noronha não estejam fixadas há muito tempo no território, suas vivências com a natureza e o entorno são importantes referências no processo de planejamento. E ainda sobre a lógica da sustentabilidade, que permeia, via de regra, o planejamento em áreas naturais, há que se considerar a qualidade de vida da população autóctone e a geração de riquezas que deve ser utilizada para reduzir a desigualdade social.

Nesse contexto, é possível conclamar a abordagem do "desenvolvimento local" a partir da qual compreende-se o planejamento público do turismo como uma atividade que envolve um processo político-social que depende de informações precisas, transparência, ética e que deve primar por soluções aceitáveis por toda a comunidade envolvida. O planejamento é mais do que um produto técnico resultante da gestão pública e deve voltar-se para a obtenção de resultados para a população. O desenvolvimento local deve ser visto como um processo de mobilização social que permita a implementação de mudanças que 
beneficiem as comunidades envolvidas do ponto de vista da sustentabilidade. Nesse sentido, o conceito de desenvolvimento local é entendido como "o processo endógeno de mobilização das energias sociais em espaços de pequena escala, que implementam mudanças capazes de elevar as oportunidades sociais, a viabilidade econômica e as condições de vida da população" (SOUZA; FERREIRA, 2011, p. 4-5).

Analisando o tema a partir da perspectiva das relações de poder aliando à gestão de áreas naturais e à relação entre comunidades tradicionais e algumas instituições envolvidas em sua gestão, deve-se considerar que

\begin{abstract}
a etnoconservação tem como eixo fundamental a garantia de reprodução da organização dos próprios povos tradicionais para a conservação e uso da natureza, é preciso levar em conta a complexa teia de relações desses grupos com a sociedade circundante. A presença de forças político-econômicas atreladas às relações capitalistas de produção converge, em muitos casos, para a desarticulação do modo de vida dessas especificidades étnicas (SILVA JÚNIOR, 2009, p. 90).
\end{abstract}

Assim, ao realizar uma proposta de turismo de base local, o planejamento deixaria de ser orientado por fatores exógenos, passando para uma organização endógena e que, portanto, beneficiaria em primeiro lugar a comunidade, para só então dimensionar benefícios a outros atores.

Na atualidade, há uma flexibilização do Sistema Nacional de Unidades de Conservação (Snuc), por exemplo, no sentido de direcionar o uso de algumas das unidades de conservação para atividades extrativistas, sobretudo quando há relação com práticas tradicionais nas comunidades. Considerando a Lei no. 9.985 que cria no Brasil o Snuc, encontra-se respaldo para a implementação de práticas turísticas com base na gestão de base comunitária. (BRASIL, 2003).

Dessa forma, a prática consta nas políticas públicas tanto de conservação da natureza quanto nas diretrizes de turismo, pois consta no Plano Nacional de Turismo (PNT 2007-2010) a partir do qual firmou-se o turismo como um vetor de desenvolvimento local e inclusão social. Cabe destacar que, ao alinhar o turismo de base comunitária com as políticas públicas, a noção de desenvolvimento aparece como pressuposto à qualidade de vida, que, por sua vez, deve ser considerada como aquela que permite que as comunidades envolvidas tenham acesso à habitação, saúde, educação, trabalho, comunicação, qualidade ambiental, além de qualidade, pluralidade e horizontalidade nos canais de decisão coletiva (HERCULANO, 2000).

\title{
Teorias de poder: coerção, incentivos e desincentivos, e informação dominante
}

Para Weber (1999), poder é a probabilidade de, em uma ação social, um ator ou vários atores imporem sua própria vontade, apesar da oposição de outrem. Ressalta que o poder economicamente condicionado não se iguala ao poder geral, pois o surgimento do poder econômico pode estar ligado a um poder previamente existente e que, frequentemente, o poder não ébuscado somente para finalidades econômicas, mas para obtenção de prestígio pessoal.

O poder, essencialmente, envolve dominação em todas as áreas da ação social. Em inúmeros casos a dominação e sua forma de execução trazem à tona relações associativas racionais. Por outro lado, quando isso não ocorre, o primeiro impulso de dominação existe a partir da estrutura e desenvolvimento da ação social para um objetivo concreto (WEBER, 1999). A dominação é, portanto, uma forma de controle sobre o outro, impondo determinado comportamento. 
Em se tratando de relações de poder no âmbito turístico, conforme Bordieu (1989, p. 7-8), é necessário identificar o poder invisível, simbólico das relações sociais, "o qual só pode ser exercido com a cumplicidade daqueles que não querem saber que lhe estão sujeitos ou mesmo que o exercem". A dificuldade na identificação de tais poderes torna a pesquisa empírica um tanto quanto complexa. Para tanto, o autor sugere que os sistemas simbólicos são estruturados e, portanto, exercem poder estruturante, o que se aproxima de alguma abordagem empírica. No turismo, a identificação dos reais interesses dos atores envolvidos em processos de planejamento é complexa e geralmente influenciada por fatores econômicos externos, o que distancia as comunidades locais de processos de tomada de decisão sobre seu território. As comunidades locais, portanto, fazem parte de um grupo social cujo poder é inferior àqueles detentores de meios financeiros, por exemplo. Essa situação é chamada de desigualdade de oportunidades por Elias (1994), onde o elo mais fraco não possui controle sobre os acontecimentos.

De acordo com Krott et al. (2014, p. 4), o poder centrado no ator é uma "relação social na qual o ator A altera o comportamento do ator B, sem reconhecer os desejos de B". De acordo com esse modelo, um ator exercendo poder dominante é o potentado e um ator recebendo poder é o subordinado. Dependendo dos recursos de poder reais em conflitos específicos, o papel de potentado e o de subordinado podem mudar rapidamente. Bramwell e Meyer (2007) afirmam que o poder é resultado de relações sociais e também é sustentado pela distribuição de recursos e pela competitividade. Relações de poder que surgem a partir de interações sociais refletem valores, significados, autoridade e controle. Tais relações podem estar em vários níveis e a teoria do poder centrada no ator especifica três elementos diferentes: coerção, incentivos e desincentivos, e informação dominante.

A coerção é uma maneira de forçar um ator a se comportar de uma certa maneira involuntária por meio de imposição de dano físico ou psicológico. Nesse caso, potentados usam força ou ameaça de força, a fim de fazer com que o subordinado aja de uma forma desejada para cooperar ou obedecer, ou seja, o potentado exige controle. A maneira mais eficaz de coerção é a ameaça, que é a percepção da violência potencial sobre o subordinado (MARIYUDI, 2011). A coerção também pode ser identificada na vida cotidiana mediante pequenos atos de controle. Se um ator possui meios legais, ele pode usar de coerção para obter vantagens.

Incentivos são definidos como aspectos financeiros ou não financeiros que podem mudar o comportamento de um subordinado por meio da motivação ou da expectativa de benefícios por agir de outra maneira do que suas próprias preferências exigiriam. $\mathrm{O}$ subordinado, mesmo quando bem informado, provavelmente persegue as metas do potentado e negligencia seus próprios interesses a fim de obter benefícios adicionais. Incentivos podem ser materiais (dinheiro ou bens) ou morais (comportamento socialmente aceitável) (MARIYUDI, 2011). Os desincentivos, por sua vez, são a retirada de benefícios por parte do potentado.

Informação dominante é o conjunto de conhecimentos detidos pelo potentado que pode causar mudança no comportamento do subordinado, levando assim a uma sensação de que este obterá benefícios. A informação é dominante porque o subordinado não é capaz ou não está disposto a verificar se é verdadeira ou falsa. Nesse caso, o subordinado ficará vulnerável a ações do potentado, que controla a situação por meio de seu conhecimento (MARIYUDI, 2011). Atores que não detêm conhecimento estão mais suscetíveis a ser controlados pelo potentado.

Poder é, portanto, a capacidade de um ator de alterar o comportamento de outro para obtenção de benefícios específicos. Por isso é importante identificar os atores baseados na teoria e analisar os seus interesses, bem como os seus elementos de poder. 
De acordo com Fortes, Gonçalves e Moritz (2010), há poder em todo corpo social, para além do Estado, denominados micropoderes por Foucault, que perpassam a vida cotidiana e os indivíduos. O turismo, nesse sentido, através do Estado, impõe políticas públicas que devem ser acatadas independentemente de participação social, na maioria dos casos. Entretanto, há resistência, já que o poder é permeável e relacional e pode ser significativamente sentido por meio do poder coercitivo nas tentativas de segmentação de mercado por parte do Estado. Nesse sentido, o mercado e a sociedade deveriam adaptar-se ao modelo de segmentação. No entanto, outras formas de segmentação surgem independente de classificações, ou seja, de baixo para cima, fazendo com que o mercado determine o direcionamento do planejamento em alguns casos, por exemplo.

Segundo Reed (1997), as relações de poder são um elemento fundamental para entender as características e resultados de um planejamento de base comunitária. Tentativas de balancear ou dispersar diferenças de poder entre atores por meio da seleção de estruturas eficazes podem ser controversas, já que aqueles que detêm o poder vão evitar distribuí-lo, entravando os processos colaborativos. Essas relações não são apenas obstáculos a serem ultrapassados mediante a criação de mecanismos mais eficientes, facilitação de condições favoráveis ou identificação de etapas, mas sim considerados endêmicos aos processos de planejamento. Relações de poder que favorecem o turismo irão exercer influência assim que a natureza da composição das comunidades se modifiquem (demografia, base econômica e politicamente nos altos escalões do governo) e, portanto, teorias de colaboração devem incorporar relações de poder como uma variável interpretativa que demonstre as razões pelas quais esforços colaborativos falham ou obtêm sucesso, em vez de apenas identificar uma variável instrumental de como o poder pode ser equilibrado.

\section{Métodos}

O trabalho de campo foi realizado no Parque Nacional Marinho de Fernando de Noronha e na Área de Proteção Ambiental de Fernando de Noronha em novembro de 2014 pela primeira autora, com o objetivo de compreender as relações de poder na ilha e, consequentemente, as possibilidades de desenvolvimento de turismo de base comunitária. As entrevistas foram feitas com os atores mais poderosos envolvidos com turismo, definidos através do processo de bola de neve. Segundo Vinuto (2014, p. 201), a técnica de amostragem não probabilística denominada bola de neve utiliza cadeias de referência para acessar grupos de atores em um universo não quantificável. Assim, ao iniciar a amostragem com o representante da instituição que administra a Área de Proteção Ambiental de Fernando de Noronha, foi possível identificar uma cadeia de referências em que um ator menciona outros com interesses comuns ou que dão suporte a essa instituição, gerando uma rede de colaboradores. Geralmente é empregado em pesquisas de conteúdo sociológico, especialmente quando se busca o conhecimento de atividades privadas ou internas, que requerem a contribuição de atores locais para que os entrevistados sejam localizados e identificados (BIERNACKI; WALDORF, 1981, p. 141).

O questionário semiestruturado (GIL, 1985) foi elaborado de maneira a identificar os elementos de poder (coerção, incentivos e desincentivos, e informação dominante) atribuídos a cada ator, permitindo quantificá-los a fim de obter uma visualização mais objetiva da distribuição de poder entre os atores mais poderosos. Cada entrevista foi gravada mediante autorização do entrevistado e notas foram feitas nos questionários destinados a satisfazer as necessidades da pesquisa, como a atribuição numérica de nível de poder, variando de 0 (nenhum poder) a 3 (alto poder), identificadas a partir das respostas do entrevistado. É importante observar que as perguntas elaboradas no questionário levam o entrevistado a expor seus elementos de poder por meio da subjetividade. Os dados foram tratados através de planilha do Excel. 
O processo de pesquisa necessitou de autorização do Instituto Chico Mendes de Conservação da Biodiversidade (ICMBio). As entrevistas tiveram duração média de uma hora cada e foram realizadas com o governo local, a administração do parque, ONG e associações, com um total de oito respondentes, que foram selecionados por meio do processo de bola de neve para garantir o acesso aos atores envolvidos com turismo. O primeiro ator a ser entrevistado foi o ICMBio e, a partir daí, o processo de bola de neve começou com os outros atores sendo mencionados como apoiadores da instituição com algum nível de influência sobre a atividade turística. Embora muitos atores/instituições baseiem-se em Recife, foi possível entrevistar aqueles com sede em Fernando de Noronha que são considerados os mais importantes para a atividade turística.

Fernando de Noronha é um arquipélago de 21 ilhas localizadas no Nordeste do Brasil e faz parte do Distrito Municipal do Estado de Pernambuco (Figura 1). Está a $545 \mathrm{~km}$ da capital Recife e faz parte da listagem das Ilhas Atlânticas Brasileiras da Unesco (REIS; HAYWARD, 2013). Fernando de Noronha é também a "ilha capital", única habitada, com uma população de 2.884 moradores, não considerando a população flutuante, que pode dobrar considerando trabalhadores transitórios (ESTIMA et al. 2014).

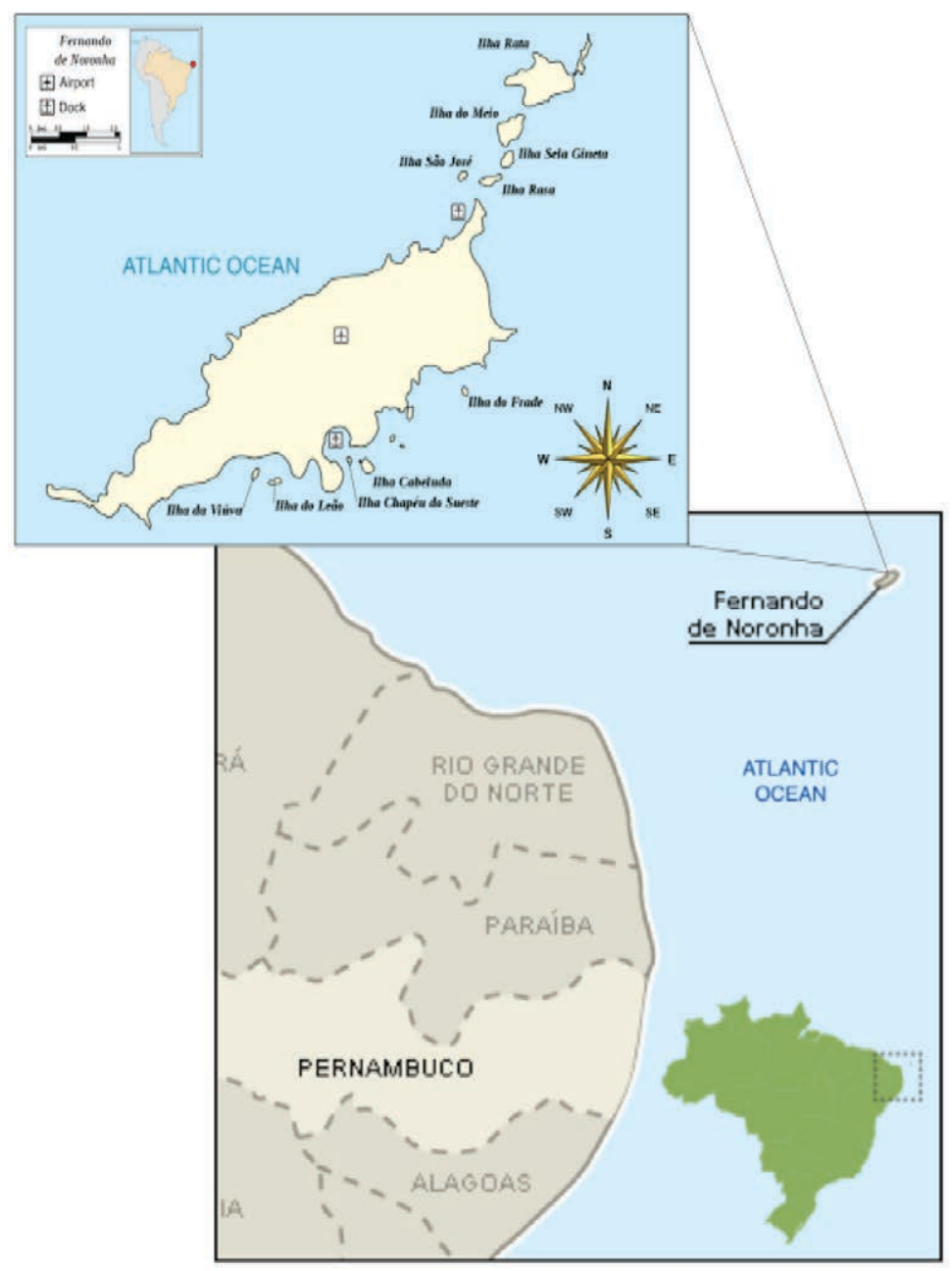

Figura 1 - Localização de Fernando de Noronha na costa brasileira

Fonte: Adaptado de https://commons.wikimedia.org/wiki/File:Map_of_Fernando_de_Noronha-en.svg 
Fernando de Noronha teve sucessivas tentativas de ocupação por exploradores holandeses e franceses após o arquipélago ter sido encontrado pelos portugueses no início do século XVI. Em 1737, Portugal teve ocupação permanente nas ilhas devido à sua posição estratégica em relação às rotas oceânicas entre América do Sul e Europa. No século XVIII uma colônia penal foi construída em Fernando de Noronha e perdurou por mais de 200 anos. Os condenados foram usados como trabalhadores da construção civil para erguer fortalezas e igrejas (MINISTÉRIO DO MEIO AMBIENTE, 2005 apud REIS; HAYWARD, 2013).

A colônia penal foi desativada em 1972, permitindo que os primeiros voos diretos para a ilha pudessem operar. O Parque Nacional Marinho de Fernando de Noronha e a Área de Proteção Ambiental de Fernando de Noronha foram criados em 1988 e 1989, respectivamente, em um esforço para preservar os ecossistemas e patrimônio cultural do arquipélago, além de permitir atividades de visitação pública e investigações científicas. O Parque Nacional Marinho abrange $112,7 \mathrm{~km}^{2}$ e a Área de Proteção Ambiental abrange $8 \mathrm{~km}^{2}$ e ambos são geridos pelo Instituto Chico Mendes de Conservação da Biodiversidade (ICMBio) (ANDRADE; GOMES; DIAS, 2009; ESTIMA et al., 2014; WIDMER, 2007).

A criação de duas áreas protegidas em Fernando de Noronha trouxe grande visibilidade ao arquipélago e o turismo começou a ser uma atividade sólida devido às suas belas paisagens e praias. Assim, os primeiros meios de hospedagem foram adaptados de casas particulares locais para atender à demanda de turistas. Além disso, os primeiros restaurantes, escolas de mergulho e serviços de aluguel de automóveis foram iniciados. As principais oportunidades de lazer para os visitantes são caminhadas, mergulho, avistamento de baleias, golfinhos e tartarugas marinhas, além da possibilidade de participação nas inúmeras atividades relacionadas ao meio ambiente oferecidas por instituições locais, em um esforço para colaborar com a sensibilização sobre a educação ambiental (ESTIMA et al., 2014). A economia de Fernando de Noronha é altamente dependente do turismo.

Em 2010 foi assinado um contrato de concessão entre o Parque Nacional Marinho de Fernando de Noronha, por meio do ICMBio, e a EcoNoronha, uma empresa privada, a fim de proporcionar facilidades e infraestrutura para algumas das atrações do parque visando melhorar os serviços de ecoturismo e diversificar oportunidades de recreação, tais como:

renovação e criação de postos de informação e controle (PICs) para suporte de visitantes; estabelecimento de lojas de conveniência com suvenires e aluguel de equipamentos; ações de conservação (redução de impactos ambientais e restauração da vegetação local); implementação e manutenção de lixeiras; uso de tecnologias sustentáveis; tratamento adequado de resíduos sólidos e líquidos; coleta e utilização de águas pluviais; implementação de infraestrutura adequada para as pessoas com deficiência; contratação e treinamento do pessoal local; criação de uma página na internet com informações sobre o parque e suas normas (ESTIMA et al., 2014; p. 224).

Atualmente, Fernando de Noronha possui forte controle da visitação, baseado em estudo de capacidade de carga, infraestrutura turística sustentável que permite excelente experiência ao visitante, além da priorização da preservação do meio ambiente.

\section{Resultados}

A Tabela 1 apresenta as definições de atores e seus respectivos exemplos em Fernando de Noronha, obtidos através das entrevistas e literatura específica. 
Tabela 1 - Atores, definições e exemplos em Fernando de Noronha:

\begin{tabular}{|c|c|c|}
\hline Ator & Definição & Exemplo \\
\hline \multicolumn{3}{|l|}{ Político } \\
\hline Político & $\begin{array}{l}\text { Ator que é eleito pelo povo para } \\
\text { exercer mandato público e pode } \\
\text { legitimar decisões }\end{array}$ & $\begin{array}{l}\text { Governo e ministros, } \\
\text { representações de partidos } \\
\text { políticos, Congresso, etc.: } \\
\text { Conselho Distrital* }\end{array}$ \\
\hline $\begin{array}{l}\text { Administração } \\
\text { pública }\end{array}$ & $\begin{array}{l}\text { Ator público que toma decisões } \\
\text { sobre problemas específicos na } \\
\text { base de normas legais gerais, } \\
\text { resolvendo tais problemas } \\
\text { e implementando medidas } \\
\text { específicas (apud Krott, 2005) }\end{array}$ & $\begin{array}{l}\text { Autoridade de conservação da } \\
\text { natureza, autoridade de uso da } \\
\text { terra, autoridade de agricultura, } \\
\text { polícia, militares, etc.: Gestão } \\
\text { Insular*, Secretaria de Ciência e } \\
\text { Tecnologia, ICMBio*. }\end{array}$ \\
\hline $\begin{array}{l}\text { Administração } \\
\text { turística }\end{array}$ & $\begin{array}{l}\text { Administração pública com foco } \\
\text { na gestão da visitação }\end{array}$ & $\begin{array}{l}\text { Departamento de turismo, } \\
\text { escritório de turismo, diretório } \\
\text { de turismo, etc.: Contur, } \\
\text { Coordenadoria de Ecoturismo*, } \\
\text { Empetur, Setur. }\end{array}$ \\
\hline Líder tradicional & $\begin{array}{l}\text { Ator legitimado para exercer } \\
\text { mandato público e pode legitimar } \\
\text { decisões em uma comunidade }\end{array}$ & $\begin{array}{l}\text { Líder de vilarejos, curandeiros, } \\
\text { autoridade tradicional, líder } \\
\text { religioso, etc.: não identificado }\end{array}$ \\
\hline Conselho & $\begin{array}{l}\text { Ator constituído por políticos, } \\
\text { líderes tradicionais ou } \\
\text { administrativos com mandato } \\
\text { público }\end{array}$ & $\begin{array}{l}\text { Conselho de turismo, conselho } \\
\text { de uso da terra, conselho de } \\
\text { controle público, conselho de } \\
\text { meio ambiente, etc.: Conselho } \\
\text { Consultivo do Parque Nacional } \\
\text { Marinho de Fernando de } \\
\text { Noronha. }\end{array}$ \\
\hline $\begin{array}{l}\text { Organização } \\
\text { doadora }\end{array}$ & $\begin{array}{l}\text { Ator que oferece recursos } \\
\text { financeiros para a resolução de } \\
\text { problemas }\end{array}$ & $\begin{array}{l}\text { Bancos nacionais e } \\
\text { internacionais, organizações, } \\
\text { etc.: Petrobras, Annenberg } \\
\text { Association, CNPq, Ministério da } \\
\text { Justiça, ABS, Secretaria de Meio } \\
\text { Ambiente e Sustentabilidade } \\
\text { de Pernambuco, Bovespa, CVC, } \\
\text { Fundação O Boticário }\end{array}$ \\
\hline Associação & $\begin{array}{l}\text { Ator que articula os interesses } \\
\text { do grupo ao qual representa } \\
\text { e tenta implementá-los por } \\
\text { meio de lobby com políticos e } \\
\text { administração pública (apud } \\
\text { Krott, 2005) }\end{array}$ & $\begin{array}{l}\text { Associação de turismo, } \\
\text { Associação de hotéis, Associação } \\
\text { de moradores, Associação de } \\
\text { meio ambiente, etc.: Associação } \\
\text { de Pousadas*, Associação de } \\
\text { Moradores, Acitur; Centro Tamar* }\end{array}$ \\
\hline $\begin{array}{l}\text { Associação de } \\
\text { apoio }\end{array}$ & $\begin{array}{l}\text { Ator que pode ser caracterizado } \\
\text { como associação, mas também } \\
\text { oferece fundos para solução de } \\
\text { problemas }\end{array}$ & $\begin{array}{l}\text { ONGs e Oscips: Centro Golfinho } \\
\text { Rotador* }\end{array}$ \\
\hline \multicolumn{3}{|l|}{ Econômico } \\
\hline $\begin{array}{l}\text { Representante } \\
\text { de grupos de } \\
\text { comunidades } \\
\text { locais }\end{array}$ & $\begin{array}{l}\text { Ator que articula os interesses } \\
\text { dos grupos de comunidades } \\
\text { locais e tenta implementá-los }\end{array}$ & $\begin{array}{l}\text { Comitês de gestão de } \\
\text { comunidades locais: não } \\
\text { identificado. }\end{array}$ \\
\hline
\end{tabular}




\begin{tabular}{|c|c|c|}
\hline Ator & Definição & Exemplo \\
\hline $\begin{array}{l}\text { Representante de } \\
\text { outros grupos }\end{array}$ & $\begin{array}{l}\text { Ator que articula os interesses de } \\
\text { outros grupos de comunidades } \\
\text { locais e tenta implementá-los }\end{array}$ & $\begin{array}{l}\text { Comitê de desenvolvimento, } \\
\text { comitê de conservação da } \\
\text { natureza, conselho gestor, etc.: } \\
\text { não identificado. }\end{array}$ \\
\hline $\begin{array}{l}\text { Empreendedor } \\
\text { turístico }\end{array}$ & $\begin{array}{l}\text { Ator que usa o turismo para } \\
\text { maximização de lucros }\end{array}$ & $\begin{array}{l}\text { Hotéis, restaurantes, operadores } \\
\text { e agências de turismo, escolas } \\
\text { de mergulho, navios de cruzeiro, } \\
\text { aluguel de barcos, planejamento } \\
\text { de eventos e outros serviços } \\
\text { relacionados: EcoNoronha*, } \\
\text { Nave, Operadora Atalaia, } \\
\text { Operadora Costa Blue. }\end{array}$ \\
\hline Consultoria & $\begin{array}{l}\text { Ator que fornece informação, } \\
\text { fundos e gestão para outro ator, } \\
\text { baseado em um contrato }\end{array}$ & Consultorias: Sebrae e Senac. \\
\hline \multicolumn{3}{|l|}{ Social } \\
\hline $\begin{array}{l}\text { Instituição de } \\
\text { pesquisa }\end{array}$ & $\begin{array}{l}\text { Ator que fornece conhecimento } \\
\text { baseado na ciência }\end{array}$ & $\begin{array}{l}\text { Universidades, centros de } \\
\text { pesquisa, etc.: Universidade } \\
\text { Federal de Pernambuco }\end{array}$ \\
\hline Mídia & $\begin{array}{l}\text { Atores que distribuem e geram } \\
\text { informação }\end{array}$ & $\begin{array}{l}\text { Mídia nacional e internacional, } \\
\text { como jornais, revistas, rádio, } \\
\text { estações de TV, etc.: TV Golfinho }\end{array}$ \\
\hline $\begin{array}{l}\text { Organização } \\
\text { religiosa }\end{array}$ & $\begin{array}{l}\text { Ator que fornece auxílio espiritual } \\
\text { ou religioso }\end{array}$ & $\begin{array}{l}\text { Igrejas, mesquitas, associações } \\
\text { religiosas ou espirituais, etc. }\end{array}$ \\
\hline Visitante & $\begin{array}{l}\text { Ator que influencia os aspectos } \\
\text { econômicos e sociais de uma } \\
\text { comunidade em busca de lazer }\end{array}$ & $\begin{array}{l}\text { Turistas e proprietários de } \\
\text { segunda residência }\end{array}$ \\
\hline
\end{tabular}

Fonte: Adaptado de Schusser et al. (2016).

*Atores entrevistados

A Tabela 1 apresenta uma ampla gama de atores relevantes que de alguma forma estão envolvidos/ interessados em turismo de base comunitária. Os mais poderosos foram identificados por meio do processo de bola de neve e estão listados a seguir. A descrição inclui uma breve definição de suas atividades em Fernando de Noronha incluindo o resultado das análises das entrevistas para cada elemento de poder (coerção, incentivos e desincentivos, e informação dominante) de cada ator, que adiante será sintetizado na Tabela 2:

- Associação de Pousadas: associação que defende os interesses dos hotéis em Fernando de Noronha. Possui direitos legais para coerção, algum meio financeiro para incentivos, porém, não possui conhecimento e expertise para informação dominante.

- Conselho Distrital: ator político que atua como uma câmara consultiva para a Assembleia Legislativa. Realiza atividades de monitoramento em Fernando de Noronha. Possui direitos legais para coerção, algum meio financeiro para incentivos e algum conhecimento e expertise para informação dominante.

- Coordenadoria de Ecoturismo: instituição de administração do turismo ligada à Gestão Insular. Desenvolve e promove projetos turísticos em Fernando de Noronha. Possui direitos legais para 
coerção, algum meio financeiro para incentivos e alto conhecimento e expertise para informação dominante.

- Concessionária EcoNoronha - Cataratas do Iguaçu S.A.: empreendedor turístico que atualmente detém o contrato para prestação de serviços de ecoturismo no Parque Nacional Marinho de Fernando de Noronha. Possui muitos direitos legais para coerção, meios financeiros para incentivos e alto conhecimento e expertise para informação dominante.

- Gestão Insular: instituição da administração pública que está dentro da autoridade do Distrito Estadual de Fernando de Noronha e está vinculada à Secretaria de Ciência e Tecnologia do Estado de Pernambuco. Possui muitos direitos legais para coerção, muitos meios financeiros para incentivos e alto conhecimento e expertise para informação dominante.

- Centro Golfinho Rotador: ONG criada para proteger e realizar pesquisas sobre o golfinho rotador e também trabalha com iniciativas de turismo em Fernando de Noronha. Possui alguns direitos legais para coerção, meios financeiros para incentivos e alto conhecimento e expertise para informação dominante.

- ICMBio - Instituto Chico Mendes de Conservação da Biodiversidade: instituição da administração pública criada para gerir áreas protegidas no Brasil. ICMBio administra o Parque Nacional Marinho Fernando de Noronha e a Área de Proteção Ambiental de Fernando de Noronha. Possui muitos direitos legais para coerção, muitos meios financeiros para incentivos e alto conhecimento e expertise para informação dominante.

- Centro Tamar - Centro Tartarugas Marinhas: associação que foi criada para proteger e realizar pesquisas sobre as tartarugas marinhas e também trabalha com iniciativas de turismo em Fernando de Noronha. Possui direitos legais para coerção, meios financeiros para incentivos e alto conhecimento e expertise para informação dominante.

Para esta análise, as seguintes definições relativas ao nível de poder dos atores entrevistados foram estabelecidas com base nos resultados empíricos deste estudo, baseados nas entrevistas e observações, bem como outros dados preexistentes na literatura:

- Nenhum poder - 0 (sem participação e/ou apoio para o turismo de base comunitária).

- Baixo poder - 1 (pouca participação e/ou apoio para o turismo de base comunitária).

- Médio poder - 2 (alguma participação e/ou apoio para o turismo de base comunitária).

- Alto poder - 3 (participação total e/ou apoio para o turismo de base comunitária).

Essas definições são então aplicadas aos atores entrevistados nesta pesquisa, como segue:

Tabela 2 - Elementos de poder para cada ator entrevistado em relação ao apoio ao turismo de base comunitária.

\begin{tabular}{|l|c|c|c|}
\hline \multicolumn{1}{|c|}{ Atores entrevistados } & Coerção & Incentivos & Informação Dominante \\
\hline Associação de Pousadas & 2 & 1 & 0 \\
\hline Conselho Distrital & 1 & 2 & 2 \\
\hline Coordenadoria de Ecoturismo & 1 & 2 & 3 \\
\hline
\end{tabular}




\begin{tabular}{|l|c|c|c|}
\hline \multicolumn{1}{|c|}{ Atores entrevistados } & Coerção & Incentivos & Informação Dominante \\
\hline EcoNoronha & 3 & 3 & 3 \\
\hline Gestão Insular & 3 & 3 & 3 \\
\hline Centro Golfinho Rotador & 1 & 1 & 3 \\
\hline ICMBio & 3 & 3 & 3 \\
\hline Centro Tamar & 1 & $\mathbf{2}$ & 3 \\
\hline
\end{tabular}

Fonte: Critério utilizado pelos autores para obter uma escala de poder por meio do questionário aplicado nas entrevistas.

\section{Discussão}

A partir da Tabela 2 podemos observar que os atores mais poderosos atuantes em Fernando de Noronha são EcoNoronha, Gestão Insular e ICMBio. Como todo o arquipélago consiste em áreas protegidas, é natural que o administrador seja um ator consideravelmente poderoso, pois tem a possibilidade de estabelecer políticas e elaborar regras de uso para o local. A EcoNoronha detém a concessão do Parque Nacional Marinho de Fernando de Noronha desde 2010 e estabeleceu uma taxa de entrada em algumas áreas específicas do parque. Nesse sentido, seu poder de coerção e incentivos/desincentivos é alto, pois regula a entrada de visitantes. A Gestão Insular, por sua vez, é órgão de administração de todo o arquipélago, submetido à capital Recife e, portanto, possui grande poder nas tomadas de decisão.

As instituições anteriormente mencionadas detêm alto grau de informações sobre Fernando de Noronha e podem definir como esses dados podem ser divulgados ou não. É importante mencionar que esses atores se apoiam mutuamente, gerando uma cadeia de interdependência e aumentando seu poder sobre o arquipélago.

Contudo, para o desenvolvimento do turismo de base comunitária, é necessário que as comunidades possuam alto poder de tomada de decisão. Para tanto, por meio dos princípios definidos anteriormente, baseados em Mitraud (2003), identificou-se o seguinte cenário, mediante análise do resultado das entrevistas e observações empíricas, destacado na Tabela 3. Para a classificação da contribuição para o turismo de base comunitária, foram atribuídos os valores baixa, média e alta, a fim de explicitar as possibilidades de desenvolvimento dessa iniciativa, como segue:

Tabela 3 - Princípios do turismo de base comunitária e observações empíricas:

\begin{tabular}{|l|c|c|}
\hline \multicolumn{1}{|c|}{ Cenário } & $\begin{array}{c}\text { Contribuição } \\
\text { para o turismo } \\
\text { de base } \\
\text { comunitária }\end{array}$ & Observação empírica \\
\hline $\begin{array}{l}\text { Contribuir para a } \\
\text { conservação do meio } \\
\text { ambiente }\end{array}$ & Alta & $\begin{array}{l}\text { As medidas de conservação da natureza em Fernando } \\
\text { de Noronha - estabelecimento de capacidade de carga } \\
\text { e monitoramento da visitação - produzem resultados } \\
\text { positivos. }\end{array}$ \\
\hline
\end{tabular}




\begin{tabular}{|c|c|c|}
\hline Cenário & $\begin{array}{l}\text { Contribuição } \\
\text { para o turismo } \\
\text { de base } \\
\text { comunitária }\end{array}$ & Observação empírica \\
\hline $\begin{array}{l}\text { Promover os valores } \\
\text { culturais das } \\
\text { comunidades, bem como } \\
\text { a sua capacidade de } \\
\text { gestão participativa }\end{array}$ & Baixa & $\begin{array}{l}\text { Alguns representantes das comunidades locais mantêm } \\
\text { seu modo de vida original, que é a pesca de subsistência } \\
\text { ou voltada ao comércio, porém, estão sujeitos às regras } \\
\text { da unidade de conservação (ICMBio). Entretanto, o único } \\
\text { meio de participação nas tomadas de decisão em relação } \\
\text { ao turismo é por meio dos conselhos consultivos das } \\
\text { áreas protegidas do arquipélago. A partir das entrevistas } \\
\text { foi possível identificar que apenas aqueles que fazem } \\
\text { parte de alguma organização civil têm representatividade } \\
\text { e outros preferem delegar essa participação ao líder } \\
\text { dessas organizações. }\end{array}$ \\
\hline $\begin{array}{l}\text { Promover a diversificação } \\
\text { econômica para melhorar } \\
\text { a qualidade de vida das } \\
\text { comunidades }\end{array}$ & Média & $\begin{array}{l}\text { A maioria dos representantes das comunidades } \\
\text { locais vivem basicamente de atividades econômicas } \\
\text { relacionadas ao turismo, porém, sofrem com a } \\
\text { gentrificação da ilha de Fernando de Noronha e com a } \\
\text { alta competitividade de empresários vindos "de fora". } \\
\text { Os pescadores remanescentes devem seguir as regras do } \\
\text { defeso estabelecidas pelo ICMBio. }\end{array}$ \\
\hline $\begin{array}{l}\text { Contribuir para a } \\
\text { integração e o equilíbrio } \\
\text { entre a conservação } \\
\text { ambiental, o respeito } \\
\text { pela cultura local e } \\
\text { diversificação das } \\
\text { atividades econômicas. } \\
\text { Deve ser realizado por } \\
\text { meio de um processo } \\
\text { participativo }\end{array}$ & Baixa & $\begin{array}{l}\text { Apesar dos esforços para conservação ambiental, pode- } \\
\text { se observar, por meio das entrevistas, que ainda há } \\
\text { problemas nesse sentido, principalmente na área urbana } \\
\text { de Fernando de Noronha, como saneamento básico, } \\
\text { tratamento adequado da água e resíduos, etc. A cultura } \\
\text { local foi altamente impactada com o estabelecimento das } \\
\text { áreas protegidas e ainda sofre interferência de alguns } \\
\text { atores externos. Em relação às atividades econômicas, } \\
\text { além do turismo, a pesca é uma delas. Porém está } \\
\text { sujeita às regras da administração das unidades de } \\
\text { conservação. O processo participativo se dá no âmbito } \\
\text { dos conselhos consultivos, entretanto, a decisão final é } \\
\text { sempre do órgão gestor, conforme informações obtidas a } \\
\text { partir das entrevistas. }\end{array}$ \\
\hline
\end{tabular}

Fonte: Adaptado de Mitraud (2003), observação empírica e análise das entrevistas.

Os grupos dominantes normalmente possuem um discurso próprio e, por estarem no poder, esse discurso torna-se oficial, atuando como uma verdade para o restante da comunidade. Os atores menos poderosos, nesse contexto, não têm seus interesses priorizados e, muitas vezes, nem meios de lutar por eles, ou seja, os interesses dos grupos minoritários não se popularizam, não se tornam públicos e não são discutidos como uma possibilidade. Isso é um entrave para o desenvolvimento do turismo de base comunitária, confirmado por Bourdieu (1989, p, 11), onde “(...) não basta notar que as relações de comunicação são, de modo inseparável, sempre, relações de poder que dependem, na forma e no conteúdo, do poder material ou simbólico acumulado pelos agentes (ou pelas instituições) envolvidos nessas relações (...)".

Este estudo identificou que a informação dominante é o elemento de poder predominante em Fernando de Noronha em detrimento de coerção e incentivos e desincentivos. A maioria dos atores entrevistados 
apresentou alto grau de detenção de informações sobre o arquipélago, caracterizando-se como o poder de utilizar e difundir esse conhecimento como lhes convier. Os atores menos poderosos nesse sentido podem ser, de certa forma, manipulados pelos mais poderosos a fim de obter vantagens ou prestígio pessoal. No entanto, pesquisas futuras podem elucidar todo o espectro de poder na rede de relações em Fernando de Noronha, pois existem muitos atores externos com interesse no arquipélago e que exercem poder por meio de outras instituições, atuando como financiadores, por exemplo.

Finalmente, inúmeros atores se apropriam do discurso ambiental com interesses diversos. Esse discurso é incorporado às práticas turísticas e ocasiona uma desvalorização dos saberes locais, considerados inferiores ao conhecimento técnico e científico. A informação dominante tem, portanto, papel fundamental nas relações de poder em Fernando de Noronha, pois determina quem possui o conhecimento técnicocientífico e sua forma mais apropriada de divulgação ou não, fazendo com que os saberes populares sejam reduzidos às esferas menos importantes no processo de produção de conhecimento.

\section{Considerações finais}

Oturismo de base comunitária deve conciliar os ideais de desenvolvimento de todos os setores da sociedade envolvidos na atividade turística, portanto, as políticas públicas devem assegurar que as demandas da população residente em todos os níveis sejam ouvidas e incorporadas aos processos de decisão. As relações de poder interferem diretamente na validação das posições no processo de tomada de decisão na gestão pública do turismo e determinam as "vozes que são ouvidas". Assim, os grupos dominantes revestem-se de um poder simbólico que se sobrepõe às demandas dos agentes menos poderosos. Cada ator possui interesses no que se refere ao desenvolvimento do turismo, e os interesses dos mais poderosos acabam por direcionar esse desenvolvimento por meio do apoio mútuo, em detrimento dos interesses das comunidades locais, normalmente mais vulneráveis econômica e socialmente.

No caso do Parque Nacional Marinho de Fernando de Noronha, os atores mais poderosos são àqueles ligados à gestão do parque, por ser uma unidade de conservação. Essa condição limita a participação pública na gestão do território, mesmo que alguns atores considerem que suas demandas são contempladas em reuniões do conselho consultivo, pois para o turismo de base comunitária, essa participação deveria ocorrer de forma ampla e irrestrita e ter impacto na realidade local.

Assim, pode-se concluir que, no caso do Parque Nacional Marinho Fernando de Noronha, as forças de poder predominantes configuram um quadro que não pode ser caracterizado como exemplo de turismo de base comunitária, uma vez que se observa o referido cenário de excessiva valorização do saber técnicocientífico em detrimento do conhecimento local por parte da maioria dos atores investigados e baixo empoderamento da população residente. Esse cenário pode ser extrapolado para outras populações do entorno de áreas protegidas no que diz respeito à informação dominante e empoderamento local, já que boa parte dos problemas são semelhantes. Cabe às entidades gestoras de unidades de conservação implantar modelos de gestão participativa que sejam mais eficazes e próximos às camadas mais excluídas dos processos decisórios. O excesso de informações técnicas pode afastar determinados grupos por ser de difícil entendimento. Os saberes locais, por outro lado, também podem ser incorporados ao planejamento do turismo, como diversos estudos demonstram, culminando em um modelo mais completo, uma vez que compreende interesses de diferentes atores do processo. 
Há, contudo, apoio por parte de alguns atores entrevistados em Fernando de Noronha, como o Golfinho Rotador, Tamar, Coordenadoria de Ecoturismo e ICMBio, para que a população residente seja mais atuante nos processos de tomada de decisão, participe de iniciativas de preservação da natureza e educação ambiental, o que pode gerar apoio mútuo em colaborações futuras.

\section{Referências}

ANDRADE, L. M. S.; GOMES, V. G.; DIAS, M. B. Desafios para o futuro sustentável da ilha de Fernando de Noronha: a visão ecossistêmica da ocupação urbana. Oculum Ensaios, v. 9, n. 10, p. 86-105, 2009.

BIERNACKI, P.; WALDORF, D. Snowball sampling: problems and techniques of chain referral sampling. Sociological methods and research, v. 10, n. 2, p. 141-163, 1981.

BORDIEU, P. $O$ poder simbólico. Rio de Janeiro: Bertrand Brasil, 1989.

BRAMWELL, B.; MEYER, D. Power and tourism policy relations in transition. Annals of Tourism Research, v. 34, n. 3, p. 766-788, 2007.

BRASIL. Lei no 9.985, de 18 de julho de 2000. Decreto nํ⒋340, de 22 de agosto de 2002. Sistema Nacional de Unidade de Conservação da Natureza - Snuc. Brasília: MMA/SBF, 2003.

BRASIL. Ministério do Turismo. Plano Nacional de Turismo 2007-2010: uma viagem de inclusão. Brasília: Ministério do Turismo, 2007.

DIEGUES, A. C. S. Sociobiodiversidade. In: FERRARO JÚNIOR, L. A. (Org.). Encontros e Caminhos: formação de educadores ambientais e coletivos educadores. Brasília: MMA - Departamento de Educação Ambiental, 2005.

ELIAS, N. A sociedade dos indivíduos. Rio de Janeiro: Zahar, 1994.

ESTIMA, D. C. et al. Concession in tourism services and partnerships in the Marine National Park of Fernando de Noronha, Brazil. Revista de Gestão Costeira Integrada, v. 14, n. 2, p. 215-232, 2014.

FORTES, L.; GONÇALVES, S.; MORITZ, T. As relações de poder e sua influência na segmentação do turismo: um diálogo foucaultiano. VII SEMINÁRIO ANPTUR. Anais... São Paulo: 2010.

GETZ, D.; JAMAL, T. B. Collaboration theory and community tourism planning, Annals of tourism research, v. 22, n. 1, p. 186-204, 1995.

GIL, A. C. Métodos e técnicas de pesquisa social. São Paulo: Atlas, 1987.

HALLACK, N.; BURGOS, A.; CARNEIRO, D. M. R. Turismo de base comunitária: estado da arte e experiências brasileiras. AmbientalMENTE sustentable, v. 1, n. 11-12, 2011.

HAYWOOD, K. M. Responsible and responsive tourism planning in the community. Tourism management, p. 105-118, 1988.

HERCULANO, S. C. A qualidade de vida e seus indicadores. In: HERCULANO, S. C. et al. (Org.). Qualidade de vida e riscos ambientais. Niterói: EdUFF, 2000.

JONES, S. Community-based ecotourism: the significance of social capital. Annals of Tourism Research, v. 32, n. 2, p. 303-324, 2005. 
KEOGH, B. Public participation in tourism in community tourism planning. Annals of tourism research, v. 17, p. 449-465, 1990.

KROTT, M. et al. Actor-centered power: the driving force in decentralized community based forest governance. Forest Policy and Economics, v. 49, p. 34-42, 2014.

MALDONADO, C. O. "Turismo rural comunitário na América Latina”. In: BARTHOLO, R.; SANSOLO, D. G.; BURSZTYN, I. Turismo de base comunitária: olhares e experiências brasileiras. Rio de Janeiro: Letra e Imagem, 2009.

MARYIUDI, A. The contesting aspirations in the forests: actors, interests and power in community forestry in Java, Indonesia. Tese (Doutorado) - Universidade de Göttingen, Alemanha, 2011.

MITRAUD, S. (Ed.). Manual de Ecoturismo de Base Comunitária: ferramentas para um planejamento responsável. Brasília: WWF Brasil, 2003.

REED, M. G. Power relations and comunity-based tourism planning. Annals of tourism research, v. 24, n. 3, p. 566-591, 1997.

REIS, A.; HAYWARD, P. Pronounced Particularity: a comparison of governance structures on Lord Howe Island and Fernando de Noronha. Island Studies Journal, v. 8, n. 2, p. 285-298, 2013.

SCHUSSER, C. et al. Comparing community forestry actors in Cameroon, Indonesia, Namibia, Nepal and Germany. Forest Policy and Economics, v. 68, p. 81-87, 2016.

SILVA JÚNIOR, R. D. Etnoconservação e o conceito de relações de poder: apontamentos teóricometodológicos. Caderno de Campo, v. 12, p. 89-105, 2009.

SIMMONS, D. G. Community participation in tourism planning. Tourism management, v. 15, n. 2, p. 98-108, 1994.

SOUZA, M. J. B.; FERREIRA; E. Planos nacionais de turismo, desenvolvimento local e sustentabilidade. XXXV ENCONTRO DA ANPAD. Anais... Rio de Janeiro: 2011.

VINUTO, J. A amostragem em bola de neve na pesquisa qualitativa: um debate em aberto. Temáticas, v. 44, p. 203-220, 2014.

WEBER, M. Economia e sociedade: fundamentos de sociologia compreensiva. v. 2. São Paulo: Editora Universidade de Brasília, 1999.

WIDMER, G. M. 0 título de patrimônio da humanidade e seus efeitos sobre o turismo em Fernando de Noronha. Tese (Doutorado) - Universidade de São Paulo, Brasil, 2007. 